\title{
Article
}

\section{Longitudinal Study of Student Attitudes in a Biology Program}

\author{
Malin J. Hansen and Gülnur Birol
}

\author{
Department of Zoology, University of British Columbia, Vancouver, BC V6T 1Z4, Canada
}

Submitted July 1, 2013; Revised January 24, 2014; Accepted January 27, 2014

Monitoring Editor: Jennifer Momsen

\begin{abstract}
This is among the first longitudinal studies to report student attitudes across $4 \mathrm{yr}$ of a university program. We found that the attitudes of students in biology become significantly more expert-like from the first year to the fourth year of the program, that is, there was a significant positive shift in students' overall percent favorable scores from 64.5 to $72 \%$, as opposed to the expert response, which averaged $90 \%$. There was a significant positive shift for the real world connection category $(78-85 \%)$, the enjoyment (personal interest) category (74-82\%), and the conceptual connections/memorization category (66-74\%). Moreover, there was a significant correlation between students' overall percent favorable scores and performance (cumulative grade point average) at the end, but not at the beginning, of the fourth year, with high-performing students having significantly more expert-like attitudes than low-performing students. The correlation between percent favorable score and performance was the strongest for the problem solving: synthesis and application category, in which the highest-performing students finished their fourth year with $90 \%$ favorable compared with $35 \%$ favorable for the lowest-performing students. A comparison of these results with previously reported results and their implications for teaching are discussed.
\end{abstract}

\section{INTRODUCTION}

Student attitudes toward a specific discipline affect their learning (Osborne et al., 2003). Preheld attitudes such as interests, beliefs, confidence, and self-efficacy, may impact how students approach learning (e.g., effort, problem-solving strategies, study habits, and critical thinking) within that discipline (Gal and Ginsburg, 1994; Perkins et al., 2005; Partin and Haney, 2012). To facilitate learning, it is therefore important that educators familiarize themselves with student attitudes and associated behaviors (i.e., approach toward learning), as well as the factors that may influence these attitudes.

Student attitudes toward science have been investigated since the mid-1960s (Ramsden, 1998; Osborne et al., 2003;

DOI: $10.1187 /$ cbe.13-06-0124

Address correspondence to: Malin J. Hansen (hansen@zoology .ubc.ca).

(C) 2014 M. J. Hansen and G. Birol. CBE—Life Sciences Education (C) 2014 The American Society for Cell Biology. This article is distributed by The American Society for Cell Biology under license from the author(s). It is available to the public under an AttributionNoncommercial-Share Alike 3.0 Unported Creative Commons License (http:/ / creativecommons.org/licenses/by-nc-sa/3.0).

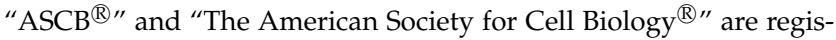
tered trademarks of The American Society for Cell Biology.
Reid, 2006), when educators started seeing a decrease in enrollment in science courses and decreased interest in science and technology-related disciplines among youth. As the association between attitudes and learning recently has become clearer, new instruments and methods to measure the impact of courses and programs on student attitudes have been developed for various science disciplines such as biology (Russell and Hollander, 1975; Quinnell et al., 2005; Semsar et al., 2011), physics (Redish et al., 1998; Adams et al., 2006), statistics (Besterfield-Sacre et al., 2001), and chemistry (Coll et al., 2002; Bauer, 2005; Berg, 2005; Barbera et al., 2008).

Many factors are correlated with student attitudes, among them performance (Weinburgh, 1995; Partin and Haney, 2012), interest (Perkins et al., 2006), gender (Felder et al., 1995; Besterfield-Sacre et al., 2001), ethnicity (Besterfield-Sacre et al., 2001; Hoang, 2008), and teaching strategies (Felder et al., 1998; Otero and Gray, 2008; Armbruster et al., 2009; Brewe et al., 2009). For some factors, such as performance, it is often difficult to distinguish between correlation and causation, which means that one has to be careful when drawing conclusions from survey results. We believe, however, that determining the correlation between attitudes and factors such as performance is essential in establishing strategies to improve student learning. In this longitudinal study, we investigated how student attitudes toward biology changed from first year 
(Pre) to fourth year (Post) and whether there was a correlation between specific attitudes and performance.

Few longitudinal studies have compared student attitudes among multiple years. Felder et al. (1998) followed students for five semesters of a chemical engineering program. They report that students who participated in classes with interactive activities reported improved attitudes, confidence, and performance throughout the program compared with students in a traditionally taught comparison group (Felder et al., 1998). In contrast, Slaughter et al. (2012) found that the attitudes of physics majors stayed the same from first to third year of a bachelor of physics program.

Our study uses a validated attitudinal survey in biology (CLASS-Bio; Semsar et al., 2011). The survey is composed of statements exploring student perceptions of the biology discipline, their approach to problem solving, their sources of knowledge, and student interest and enjoyment of biology within the expert-novice continuum (Semsar et al., 2011). Our study thus sheds light onto our understanding of how the attitudes of biology students compare with those of experts and how these attitudes change over the course of a degree program.

\section{METHODS}

\section{The Context}

The University of British Columbia (UBC) is a large North American research- and teaching-intensive institution with 7000 students majoring in the Faculty of Science and is located in Vancouver, Canada. The biology program, which is part of the life sciences, is one of the largest among the science programs.

The UBC science students are among the top within the province as well as across Canada. Incoming students are accepted to the Faculty of Science with very high secondary school grade averages (92.5\%), and only $10 \%$ of them do not reach second year. Approximately $70 \%$ of the incoming students graduate from their programs in $5 \mathrm{yr}$. Based on a survey on their goals after graduation conducted in 2007 in two multisection first-year biology courses, $\sim 45 \%$ of the students listed continuing on in a professional degree program, such as medical or dental school; $\sim 15 \%$ listed entering a job related to their degree; $\sim 10 \%$ listed going to a graduate school related to their degree program; another $10 \%$ listed a graduate school unrelated to their degree; and 20\% were undecided.

The biology program at UBC is offered by the departments of botany and zoology. In the past several years, the program has undergone a major curriculum revision that resulted in the following program options: one major, eight honors programs, and three combined honors programs. The new program is designed to increase the quality and relevance of the students' experiential learning, while taking advantage of existing strengths in the program. The experiential learning is defined as learning gained by experiencing the process of science, including performing observations and experiments in laboratories, interpreting data, and improving concept construction in tutorials and other small-group learning environments. Recent initiatives (including the Faculty of Science Strategic Priorities Fund and the Carl Wieman Science Education Initiative [www.cwsei.ubc.ca]) made it practical to undertake a revision of the biology curriculum. As a result of this undertaking, five second-year core courses, as well as a couple of first- and third-year courses within the biology program, are in the process being transformed from a traditional teacher-centric format to a more learner-centric format. The transformation of courses involves clear articulation of course learning goals, involvement of activities and peer discussions, and incorporation of personal-response systems such as clickers. The in-class activities allow students to practice problem solving and reflect on their learning. The results from a program-wide survey in 2012 revealed that $69 \%$ of all the courses within the program currently use course-level learning goals, while $43 \%$ use topic-specific learning goals (unpublished data). While most of the courses that are in transformation as described above have implemented some form of interactive activities and peer discussion, we currently have little information about the remaining courses within the program.

\section{The CLASS-Bio Survey}

We used a validated biology attitudinal survey, CLASS-Bio, which was developed in collaboration with the University of Colorado-Boulder and the University of British Columbia (Semsar et al., 2011). CLASS-Bio examines how students perceive the field of biology on the novice-expert continuum, providing a direct comparison of student perceptions with expert perceptions (Semsar et al., 2011). Hammer (1994) proposed three main areas that characterize how experts and novices view a discipline: content and structure of knowledge, source of knowledge, and problem-solving approaches, all of which are discussed in detail elsewhere (Hammer, 1994). Briefly, experts differ significantly from novices, because they have a deeper conceptual knowledge of a discipline and hold more sophisticated views about how scientific knowledge is obtained, expanded, and structured, and they know how to approach problem solving (Semsar et al., 2011). The CLASSBio consists of 31 statements grouped into seven categories: 1) real world connection; 2) enjoyment (personal interest); 3) problem solving: reasoning; 4) problem solving: synthesis and application; 5) problem solving: strategies; 6) problem solving: effort; and 7) conceptual connections / memorization. The agreement of the respondent to each statement was rated using a 5-point Likert scale (strongly agree to strongly disagree). Each statement has been validated with an average consensus among experts (biology faculty) of 90\% (Semsar et al., 2011).

The statements in the CLASS-Bio are not course specific, but are designed to measure perceptions about the biology discipline itself. The survey is available at www.colorado .edu/sei/class/CLASS-Bio.html.

\section{Data Collection}

This study was conducted between 2009 and 2013 at UBC. The study adhered to the Approved Board of Ethics protocols (protocol numbers H07-01303 and H07-01633). The survey was administered online at the beginning of the term in two large, multisection, first-year biology courses (BIOL 112 and 121) in the Fall of 2009 and 2010. BIOL 112 (Biology of the Cell) and BIOL 121 (Ecology, Evolution, and Genetics) are mandatory survey courses for the Faculty of Science, in most programs in life sciences and across UBC (such as the 
faculties of Education, Forestry, Land and Food Systems), as well as being required prerequisite courses for most health sciences programs (such as the faculties of Medicine and Dentistry). Participation was voluntary; however, as an incentive, students were given $0.5-1.0 \%$ bonus marks for their participation. Out of a total of 2298 students, 1827 students completed the survey, that is, the participation rate was $80 \%$.

The fourth-year responses were also collected through an online survey, but the survey was not associated with a course. Instead, all students in the fourth year of the biology program were invited to participate through email correspondence sent by the associate head of the biology program once per term from 2012 to 2013. Students' names were entered into a prize draw to win one of the two gift cards as an incentive for participation. Out of a total of 1687 students, 459 students completed the survey, that is, the participation rate was $27 \%$.

In total, 2203 students participated in the survey. While some of the students (Matched, $n=83$ ) completed it both in their first year (Pre) and in their fourth year (Post), the majority of the students (Unmatched, $n=2120$ ) completed it only once, that is, either Pre $(n=1744)$ or Post $(n=376)$.

\section{Data Analysis}

The scoring of a given statement was categorized as follows: disagree, if respondents chose "strongly disagree" or "disagree" on the Likert scale; neutral, if they chose "neutral"; and agree, if they chose "agree" or "strongly agree." Responses that were in agreement with expert responses were referred to as favorable, while responses that were in disagreement with expert responses were referred as unfavorable (Semsar et al., 2011).

To explore overall changes in attitudes for Matched students, we performed a paired $t$ test to compare overall Pre and Post percent favorable scores. Because the categories are interdependent, due to some overlap among the statements, we used separate paired $t$ tests to analyze differences between Pre and Post scores for the seven categories. This is justified, because we found a significant overall difference between Pre and Post scores. In addition, we used single correlations to explore the relationship between performance (cumulative grade point average [GPA]) and Pre and Post scores for each category. The cumulative GPA (Canadian universities use a
0-100\% GPA scale) was calculated as the average grade of all courses that had been completed at UBC by the end of the fourth year.

We also compared Matched and Unmatched students scores in both first and fourth year to find out whether the two groups differed from each other. We used a $t$ test to explore the overall difference between Matched and Unmatched students in first year and in fourth year, as well as separate $t$ tests to analyze differences in the seven categories. In addition, we used single correlations to explore the relationship between performance (cumulative GPA) and percent favorable scores of each category for Unmatched fourth-year students. The percent favorable scores were arcsine transformed to meet the assumptions of the parametric statistical tests. For all the statistical analyses, significant difference was determined by a $p$ value of less than or equal to 0.05 . The statistical analyses were performed using the JMP statistical software package.

\section{RESULTS AND DISCUSSION}

\section{Overall Shifts in Attitudes of Matched Students}

Matched students $(n=83)$ had more expert-like attitudes toward biology in their fourth year than in their first year. There was a significant positive overall shift from 64.5 to $72 \%$ by the end of the fourth year $(F=14.80, p=0.0002$; Figure 1a), as opposed to the expert response averaging $90 \%$.

When Pre and Post scores were compared for individual categories, there was a significant positive shift for the real world connection category $(78-85 \%, F=7.52, p=0.0075)$, the enjoyment (personal interest) category $(74-82 \%, F=$ 8.67, $\mathrm{p}=0.0042)$, the problem-solving: reasoning category $(74-80 \%, F=4.12, p=0.0455)$, and the conceptual connections/memorization category $(66-74 \%, F=4.32, p=0.0408$; Figure 1b).

In addition, the overall average percent favorable score (Pre and Post combined) differed significantly among the statement categories ( $F=7.80, p<0.0001$; Figure $1 b)$. Not surprisingly, students had more expert-like views on categories related to their personal interests and life (the score ranged from 75 to $85 \%$ favorable for categories such as real world connection, enjoyment [personal interest] and problem solving: reasoning), than on categories related to problem solving (the score ranged from 55 to $75 \%$ favorable for categories

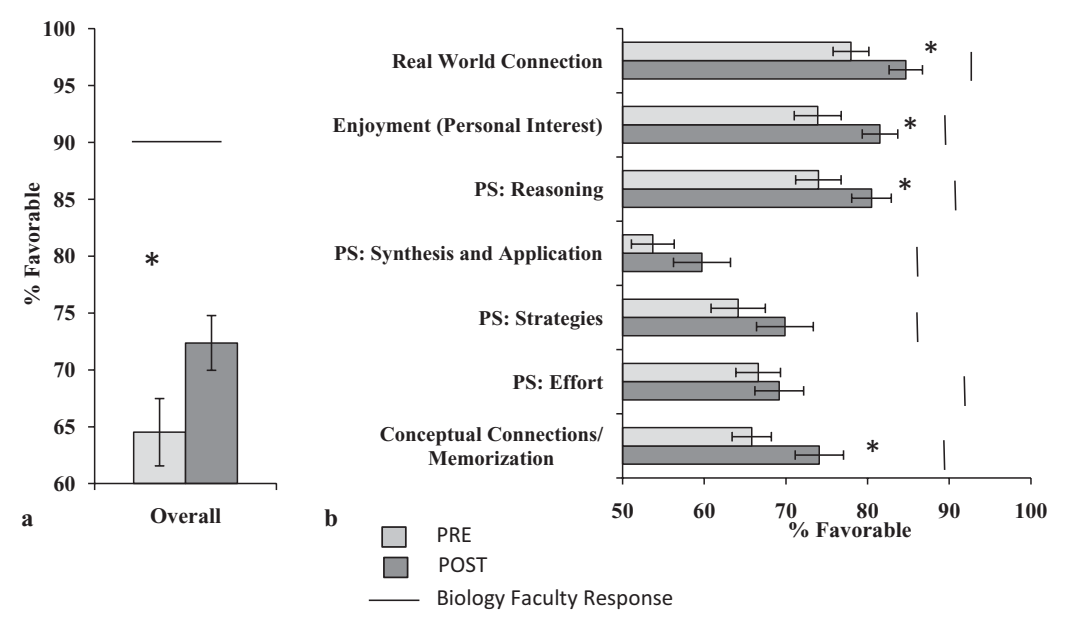

Figure 1. (a) Overall Pre and Post favorable scores (percent agreement with experts) for Matched students $(n=83)$ and the average biology faculty response. Students $(n=83)$ entered the first year of the program with an overall average percent favorable score of 64.5 . The overall average percent favorable score increased significantly to $72(F=14.80, p=$ 0.0002 ) by the end of the fourth year. (b) Pre and Post percent favorable scores for all statement categories for Matched $(n=83)$ and the average biology faculty response for these categories. Students' attitudes were significantly more expert-like for categories such as real world connection, enjoyment (personal interest), problem solving: reasoning, and conceptual connections/memorization than for categories such as problem solving: synthesis and application, problem solving: strategies, and problem solving: effort. Asterisks indicate a significant difference of $p<0.05$. Error bars indicate SE. 
such as problem solving: synthesis and application, problem solving: effort, problem solving: strategies, and conceptual connections/memorization; Figure 1b).

While earlier studies using the same or similar surveys have reported similar results, that is, more expert-like attitudes in fourth-year students than in first-year students (Bates et al., 2011; Semsar et al., 2011), our study is among the first to report longitudinal results of student attitudes over a 4-yr period. When using CLASS for physics, Slaughter et al. (2012) found no significant shifts in the attitudes of physics majors from first to third year of a bachelor of physics program. However, they reported a percent favorable score of 70 across the $3 \mathrm{yr}$, which is similar to the score of our Matched students. In addition, our first-year (Pre) and fourth-year (Post) percent favorable scores for the Matched students (overall and for individual categories) were comparable to first- and fourthyear student responses (nonlongitudinal) collected at other institutions using the same survey (Semsar et al., 2011).

Our study suggests there is room for attitudinal improvement for students after $4 \mathrm{yr}$ in a university program. This is especially true for categories such as problem solving: synthesis and application, for which the average score was $<60 \%$ for Matched students. Although we cannot determine where students should be on the expert-novice continuum at the end of a 4-yr degree program, we find it peculiar that the average percent favorable score for categories such as real world connection and enjoyment (personal interest) is more than $20 \%$ higher than for most categories related to problem solving. Furthermore, our results show that $\sim 50 \%$ of the Matched students agree with statements such as: "After I study a topic in biology and feel that I understand it, I have difficulty applying that information to answer questions on the same topic" and "When I am answering a biology question, I find it difficult to put what I know into my own words." Should we expect students' confidence and effort in problem solving to be higher than this after $4 \mathrm{yr}$ in a university program? We encourage science educators to consider this question when designing courses and programs and to set goals for their students both in terms of student achievement and of attitudes and confidence.

\section{Performance Differences}

There was no significant correlation between the overall percent favorable score and performance (cumulative GPA) of the Matched students at the beginning of the program. There was a significant correlation between percent favorable score and performance for the enjoyment (personal interest) category only, in which high-performing students had significantly more expert-like attitudes than low-performing students at the beginning of the program $\left(R^{2}=0.05, F=4.63, p=0.0345\right.$; Figure $\left.2 \mathrm{c}\right)$. By the fourth year, however, there was a significant correlation between students' overall percent favorable score and their performance $\left(R^{2}=0.07, F=6.27, p=0.0143\right.$; Figure 2a) and for the real world connection category $\left(R^{2}=0.10, F=\right.$ 9.38, $p=0.003$; Figure $2 b$ ) and the problem solving: synthesis and application category $\left(R^{2}=0.12, F=11.03, p=\right.$ 0.0013 , Figure 2e), with high-performing students displaying significantly more expert-like attitudes than low-performing students.
Our study suggests that all students start the program with relatively novice-like attitudes toward biology $(<65 \%)$, especially in categories related to problem solving and conceptual understanding. By fourth year (Post), however, high-performing students had significantly more expert-like attitudes than low-performing students. This implies that attitudes in the beginning of the program do not predict performance at upper program levels.

Because we cannot claim causality between performance and attitudes, it is not clear whether lower grades lead to negative attitudinal shifts or little improvement in attitudes or whether deteriorating attitudes lead to low grades over the course of the program. However, it is important to note that, while there were significant correlations between performance and attitudinal Post scores related to problem solving and real world connection, there was no correlation between performance and attitudinal Post scores related to personal interest. Also, while the personal interest in biology increases significantly for low-performing students, it does not change at all for high-performing students (Figure 2c). This suggests that, although high- and low-performing students may differ in terms of confidence, there is little difference in their interest in and enjoyment of biology. Our results therefore suggest that there may not be as strong a correlation between personal interest and attitudes as previously reported (Perkins et al., 2006).

Partin and Haney (2012) found that self-efficacy, that is, an individual's perceived level of competence, was strongly correlated with performance in undergraduate biology courses. Bandura (1986) suggests that individuals with high selfefficacy for a task will persist at the task until it has been completed, while individuals with low self-efficacy often give up quickly when experiencing difficulty. Because the CLASSBio survey does not have a category measuring self-efficacy specifically, we cannot draw direct conclusions based on our data. Several of the survey statements in the problem solving: effort category, however, are related to self-efficacy, e.g., "When I am not pressed for time, I will continue to work on a biology problem until I understand why something works the way it does" and "I do not spend more than a few minutes stuck on a biology question before giving up or seeking help from someone else." Our study did not find a correlation between percent favorable score for statements in the problem solving: effort category and performance.

\section{Comparison between Matched and Unmatched Students}

When Matched students' overall Pre score was compared with the rest of the first-year students' Pre score (Unmatched, $n=1744)$, the Matched students had significantly more expert-like attitudes than the Unmatched students $(F=6.30$, $p=0.0122$; Figure 3a). Specifically, the Matched students had significantly more expert-like attitudes for the enjoyment (personal interest) category $(F=10.46, p=0.0012)$ and the real world connection category $(F=7.74, p=0.0055)$. In contrast, when Matched students' Post scores were compared with the rest of the fourth-year students' Post scores (Unmatched, $n=376$ ), there was no significant difference between the two groups (Figure $3 b$ ). We found significant correlations between performance (cumulative GPA) and percent favorable scores of Unmatched fourth-year students for the problem solving: 

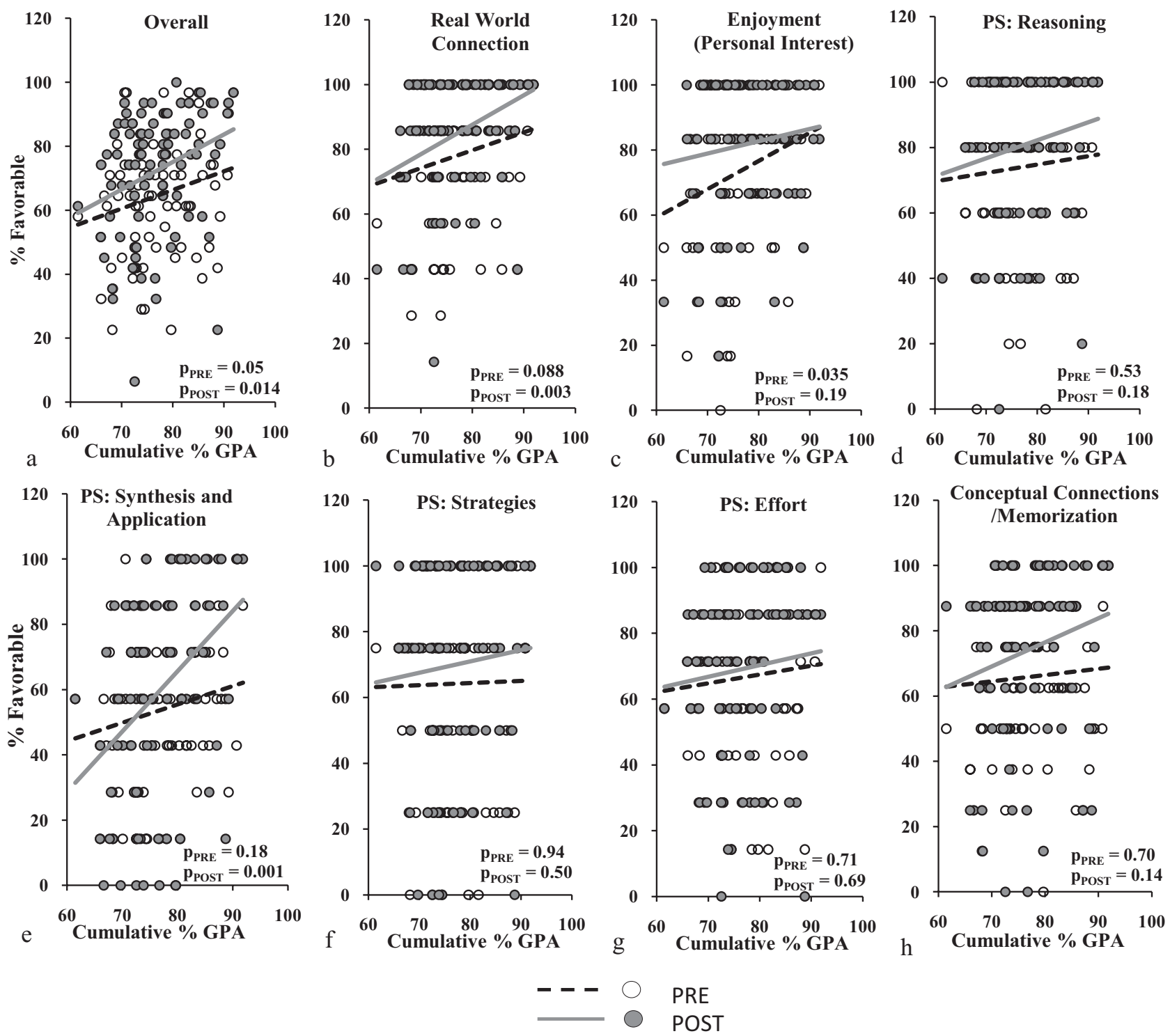

Figure 2. Correlations between performance (cumulative GPA) and Pre and Post percent favorable scores for Matched ( $n=83$ ) students.

synthesis and application category $\left(R^{2}=0.05, F=10.59, p=\right.$ $0.0013)$, problem solving: strategies category $\left(R^{2}=0.02, F=\right.$ $4.29, p=0.0395)$, and problem solving: effort category $\left(R^{2}=\right.$ $0.02, F=5.11, p=0.0248$ ), with high-performing students showing significantly more expert-like attitudes than lowperforming students.

Matched students may have had more expert-like attitudes in their first year than Unmatched students, because most of the Matched students ended up majoring in biology, while some of the Unmatched students changed their major. Majors have been shown to have more expert-like attitudes than nonmajors at the beginning of a program (Adams et al., 2006; Perkins and Gratny, 2010; Semsar et al., 2011). Because there was no overall significant difference in the attitudes of our Matched and Unmatched students by the fourth year of the biology program and because the correlation between performance and percent favorable scores were similar for these two groups, we are confident that our Matched student group represents the fourth-year students who took the survey.

\section{Implications for Teaching}

There is evidence in the science education literature that teaching strategies may affect student attitudes. However, while it is common for courses to shift their focus from being teacher-centric to learner-centric by implementing activities to engage students, interactive activities may not be enough to improve student attitudes (Perkins et al., 2005; Redish and Hammer, 2009). For example, Perkins et al. (2005) found that the deterioration of student attitudes after one term of introductory physics were the same in courses taught using traditional lectures and courses taught using interactive activities. In contrast, they found that student attitudes stayed 

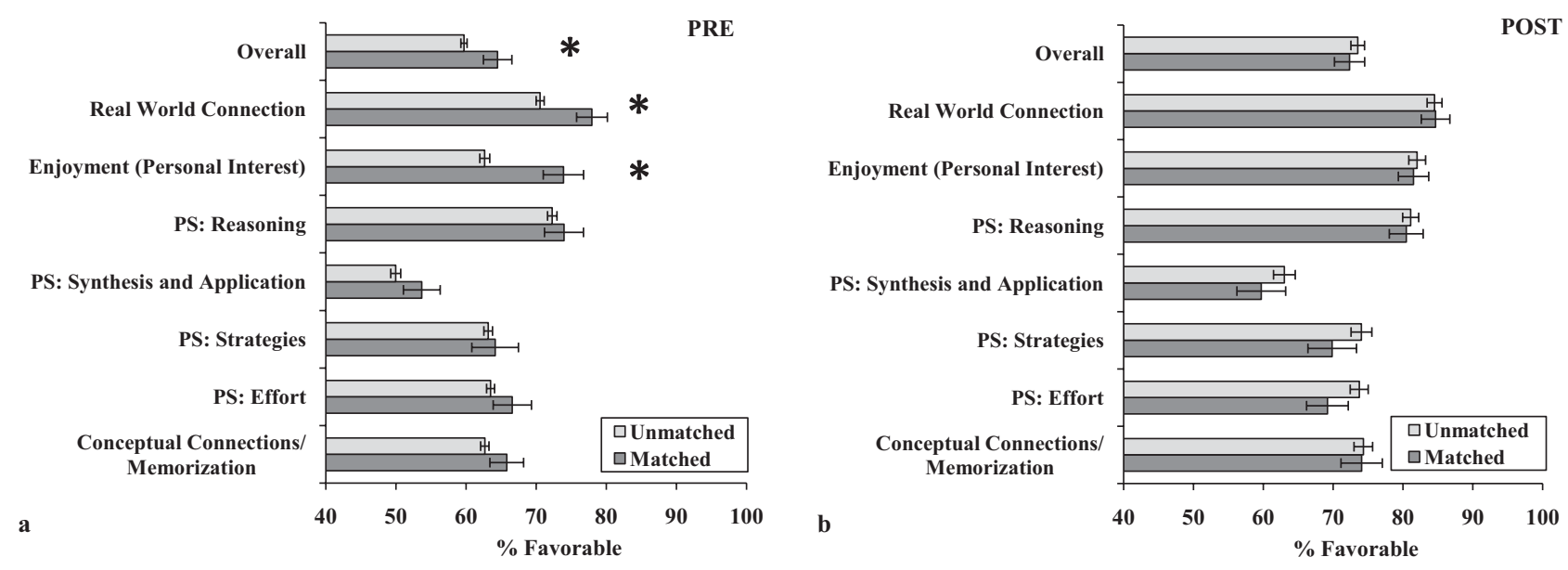

Figure 3. (a) Overall, Matched $(n=83)$ students had significantly more expert-like attitudes than the Unmatched $(n=1744)$ students $(64.5 \%$ vs. $59.5 \%, F=6.30, p=0.0122$ ). Matched students had significantly more expert-like attitudes for the enjoyment (personal interest) category $(F=10.46, p=0.0012)$ and the real world connection category $(F=7.74, p=0.0055)$. (b) There was no significant difference between the Matched $(n=83)$ and the Unmatched $(n=376)$ students for any statement categories in the fourth year. Asterisks indicate a significant difference of $p<0.05$. Error bars indicate SE.

the same or became more expert-like in courses taught using methods specifically aimed at improving student attitudes (Perkins et al., 2005). Brewe et al. (2009) found that student attitudes toward physics became more expert-like in a transformed physics class based on activities in which students were required to practice science through building, validating, and deploying models. Likewise, Redish and Hammer (2009) and Otero and Gray (2008) found that using an epistemological curriculum in addition to inquirybased learning activities led to more expert-like attitudes. Such a curriculum emphasizes epistemological framing, in which students focus on making sense of scientific concepts; scientific thinking, in which students practice problem solving and critical thinking; and metacognition, in which students reflect on their own learning. These studies suggest that, while many interactive activities increase student learning, they may not lead to more expert-like attitudes. Instead, inquiry-based activities that emphasize the nature of scientific knowledge, the scientific method, and metacognition may be required.

Our results show that students' overall percent favorable score in problem solving is $<75 \%$ after $4 \mathrm{yr}$ in a university program. Also, attitudes related to synthesis and application deteriorated over the course of the program in low-performing students. This suggests that students in biology programs, specifically students with lower grades, may benefit from activities that emphasize problem solving, model building, and metacognition. Instructors can also provide study support and guidance that benefit low-performing students. For example, Deslauriers et al. (2012) used interventions to improve the study strategy of low-performing students in physics and earth and ocean science. Their results show that lowperforming students who learn to study more efficiently do better on exams.

The implementation of interactive engagement into biology courses is an ongoing effort at UBC. With the new curriculum now in place, courses are being developed and/or transformed to incorporate carefully designed activities to promote learning. As course transformations reach their completion, we anticipate improvements in both student attitudes and their learning of biology. This study serves as baseline data, and we suggest that the biology program (UBC) continue to collect attitudinal data as part of its regular program evaluation.

\section{CONCLUSION}

This is the first longitudinal study conducted across a biology program that explores student attitudes toward biology. We used a validated attitudinal survey, CLASS-Bio, to capture the change in student views of biology across a 4-yr period. The major finding of the study was that students begin the biology program with similar attitudes toward biology, but, by the fourth year, high-performing students have significantly more expert-like attitudes than low-performing students. In addition, while students became more expert-like in their general interest in biology and real world connection, there was little change in attitudes related to problem solving. In general, we found that student attitudes after $4 \mathrm{yr}$ of a degree program are, irrespective of performance, still far from expert-like.

\section{ACKNOWLEDGMENTS}

This work is fully funded by the Carl Wieman Science Education Initiative-Life Sciences and partly funded by the Science Center for Learning and Teaching at the UBC. The authors thank Drs. Carl Wieman, Sarah Gilbert, George Spiegelman, and Trish Schulte, and the CWSEI Science Teaching and Learning Fellows for their support and feedback; Ms. Shona Ellis for her help with student recruitment for the survey participation; Dr. Ido Roll for his expert opinion on the statistical analysis; Katherine Semsar, Jennifer Knight, and Michelle Smith for sharing their data on expert agreements on the CLASS-Bio; and countless faculty members in the biology program of UBC for their support and allowing us run the survey in their courses. The authors also thank all students who participated in this work. 


\section{REFERENCES}

Adams WK, Perkins KK, Podolefsky NS, Dubson M, Finkelstein ND, Wieman CE (2006). New instrument for measuring student beliefs about physics and learning physics: The Colorado Learning Attitudes About Science Survey. Phys Rev Spec Top Phys Educ Res 2, 010101.

Armbruster P, Patel M, Johnson E, Weiss M (2009). Active learning and student-centred pedagogy improve student attitudes and performance in introductory biology. CBE Life Sci Educ 8, 203213.

Bandura A (1986). The explanatory and predictive scope of selfefficacy theory. J Soc Clin Psychol 4, 359-373.

Barbera J, Adams WK, Wieman CE, Perkins KK (2008). Modifying and validating the Colorado Learning Attitudes About Science Survey for use in chemistry. J Chem Educ 85, 1435-1439.

Bates SP, Galloway RK, Loptson C, Slaughter KA (2011). How attitudes and beliefs about physics change from high school to faculty. Phys Rev Spec Top Phys Educ Res 7, 020114.

Bauer CF (2005). Attitude toward chemistry: a semantic differential instrument for assessing curriculum impacts. J Chem Educ 82, 18641870.

Berg CAR (2005). Factors related to observed attitude change toward learning chemistry among university students. Chem Educ Res Pract 6, 1-18.

Besterfield-Sacre M, Moreno M, Shuman LJ, Atman CJ (2001). Gender and ethnicity differences in freshmen engineering student attitudes: a cross-institutional study. J Eng Educ 90, 477-489.

Brewe E, Kramer L, O’Brien G (2009). Modeling instruction: positive attitudinal shifts in introductory physics measured with CLASS. Phys Rev Spec Top Phys Educ Res 5, 1-5.

Coll RK, Dalgety J, Salter D (2002). The development of the chemistry attitudes and experiences questionnaire (CAEQ). Chem Educ Res Pract Eur 3, 19-32.

Deslauriers L, Harris SE, Lane E, Wieman CE (2012). Transforming the lowest-performing students: an intervention that worked. J Coll Sci Teach 41, 80-88.

Felder RM, Felder GN, Dietz EJ (1998). A longitudinal study of engineering student performance and retention. V. Comparisons with traditionally-taught students. J Eng Educ 87, 469-480.

Felder RM, Felder GN, Mauney M, Hamrin CE Jr., Dietz EJ (1995). A longitudinal study of engineering student performance and retention. III. Gender differences in student performance and attitudes. J Eng Educ 84, 151-163.

Gal I, Ginsburg L (1994). The role of beliefs and attitudes in learning statistics: towards an assessment framework. J Stat Educ 2(2).

Hammer D (1994). Epistemological beliefs in introductory physics. Cognition Instruct 12, 151-183.

Hoang TN (2008). The effects of grade level, gender, and ethnicity on attitude and learning environment in mathematics in high school. Int Electronic J Mathemat Educ 3, 47-59.
Osborne J, Simon S, Collins S (2003). Attitudes towards science: a review of the literature and its implications. Int J Sci Educ 25, 10491079.

Otero VK, Gray KE (2008). Attitudinal gains across multiple universities using the Physics and Everyday Thinking curriculum. Phys Rev Spec Top Phys Educ Res 4, 020104.

Partin ML, Haney JJ (2012). The CLEM model: path analysis of the mediating effects of attitudes and motivational beliefs on the relationship between perceived learning environment and course performance in an undergraduate non-major biology course. Learn Environ Res 15, 103-123.

Perkins KK, Adams WK, Pollock SJ, Finkelstein ND, Wieman CE (2005). Correlating student beliefs with student learning using the Colorado Learning About Science Survey. In: 2004 Physics Education Research Conference, CP790, ed. J Marx, P Heron, and S Franklin, Melville, NY: American Institute of Physics, 61-65.

Perkins KK, Gratny M (2010). Who becomes a physics major? A longterm longitudinal study examining the roles of pre-college beliefs about physics and learning physics, interest, and academic achievement. In: 2010 Physics Education Research Conference, CP1289, Melville, NY: American Institute of Physics, 253-256.

Perkins KK, Gratny MM, Adams WK, Finkelstein ND, Wieman CE (2006). Towards characterizing the relationship between students' interest in and their beliefs about physics. In: 2005 Physics Education Research Conference, CP818, ed. J Marx, P Heron, and S Franklin, Melville, NY: American Institute of Physics, 137-140.

Quinnell R, May E, Taylor C, Peat M (2005). Creating a reliable instrument to assess student's conceptions of studying biology at tertiary level. In: Proceedings of Blended Learning in Science Teaching and Learning Symposium, Sydney, NSW, Australia: UniServe Science, pp. 87-92.

Ramsden JM (1998). Mission impossible? Can anything be done about attitudes to science? Int J Sci Educ 20, 125-137.

Redish EF, Hammer D (2009). Reinventing college physics for biologists: explicating an epistemological curriculum. Am J Phys 77, 629-642.

Redish EF, Saul JM, Steinberg RN (1998). Student expectations in introductory physics. Am J Phys 66, 212-224.

Reid N (2006). Thoughts on attitude measurement. Res Sci Technol Educ 24, 3-27.

Russell J, Hollander S (1975). A Biology Attitude Scale. Am Biol Teach 37, 270-273.

Semsar K, Knight JK, Birol G, Smith MK (2011). The Colorado Learning Attitudes about Science Survey (CLASS) for use in Biology. CBE Life Sci Educ 10, 268-278.

Slaughter KA, Bates SP, Galloway RK (2012). A longitudinal study of the development of attitudes and beliefs towards physics. AIP Conf Proc 1413, 359-362.

Weinburgh M (1995). Gender differences in student attitudes toward science: a meta-analysis of the literature from 1970 to 1991. J Res Sci Teach 32, 387-398. 